\title{
INDÚSTRIA CULTURAL: ALGUMAS DETERMINAÇÕES POLÍTICAS, CULTURAIS E SOCIAIS NA EDUCAÇÃO
}

\author{
Leda Aparecida Pedroso*
}

O Brasil, pelas suas condiçōes particulares desde meados do século 20, é um dos países onde essa famosa indústria cultural deitou raizes mais fundas e por isso mesmo é um daqueles onde ela, já solidamente instalada e agindo em lugar da cultura nacional, vem produzindo estragos de monta.

(Milton Santos)

\begin{abstract}
RESUMO: Este artigo analisa a persistência da marginalização e da exclusão social apesar da pretensa democratização da informação que estaria sendo viabilizada pela introdução de novas tecnologias nos meios de comunicação de massa, nas escolas e nos currículos escolares. Essas novas tecnologias (TV, vídeos, computadores conectados à Internet), tendo sido apropriadas pela Indústria Cultural, continuam "produzindo" analfabetos e os chamados anal-fabetos funcionais bem como, mais recentemente, os "analfabetos ponto com". Tais recursos não vêm resultando em maior conhecimento e participação dos indivíduos nas decisões políticas e nos bens socioculturais que ficam restritos a uma pequena minoria, a qual se poderia chamar pelo substantivo "cidadão". A tentativa de superação dos modismos pedagógicos, buscando uma educação crítica e criativa em direção a objetivos emancipadores, é tarefa ainda a ser realizada.
\end{abstract}

Palavras-chave: Indústria Cultural, Tecnologias e Exclusão Social, Educação e Tecnologias.

* Professora do Departamento de Ciências da Educação (FCL/Unesp/Araraquara) e coordenadora do Grupo de Estudos e Pesquisas: Indústria Cultural e Educação (Gepice).E-mail: ledapedroso@uol.com.br 
A chamada "Indústria Cultural", termo usado por Adorno \& Horkheimer, na Dialética do Esclarecimento, em 1947, ocupa hoje lugar destacado nas sociedades modernas. Pode-se mesmo dizer que em alguns aspectos sociais, políticos e econômicos, ou se está na mídia ou, estando fora dela, será excluído da sociedade que amplia cada vez mais o binômio inclusão/exclusão.

Infelizmente, no Brasil, as pressōes sociais presentes no período da chamada "transição democrática" não foram suficientes para superar o "sistema dual", ${ }^{1}$ onde existem mecanismos efetivos de participação e influência somente para os que estão integrados (grupos dominantes social e economicamente e segmentos organizados da sociedade). Para os que permanecem de fora - marginalizados e incapazes de se organizar - resta a possibilidade de participar das eleições quando, então, tornam-se objeto de manipulação política. Estes são os chamados "cidadãos de segunda classe" (Weffort, 1992).

A distância entre esses dois segmentos vem aumentando. Embora a censura política dos anos de regime militar tenha sido suspensa, convivemos hoje com a censura dos grupos economicamente dominantes e, porque não dizer, com a censura dos chamados jornalistas "chapa branca", encarregados de transformar fatos corriqueiros em grandes feitos político-administrativos dos governantes, ou de omitir e maquiar fatos desabonadores de sua imagem. É a mídia transformando a política em espetáculo, usando para isso os novos meios tecnológicos e do campo da informática para produzir efeitos considerados desejáveis pelos detentores políticos e econômicos do poder.

Nesse tipo de organização socioeconômica, muda o sentido do trabalho em uma sociedade que se pretende democrática. Emir Sader (2000) considera que

uma sociedade justa, democrática, hoje, é, antes de tudo, uma sociedade do trabalho. Isto é, uma sociedade em que o direito ao trabalho é garantido para todos, que todos vivam de seu trabalho, sem explorar o trabalho alheio.

Diferentemente, hoje, os indivíduos têm de se submeter às novas exigências impostas pelo mercado de trabalho como primeiro requisito para se inserir na sociedade e candidatar-se à obtenção dos direitos da cidadania. Já não basta mais obter a duras penas um diploma. É preciso dominar as novas tecnologias da informática, falar inglês e, no mínimo, possuir um endereço eletrônico para se candidatar a um emprego minimamente decente e, então, galgar o primeiro passo para conseguir usufruir de alguns bens (materiais e culturais) inerentes à condição de cidadão. Como diz Gilberto 
Dimenstein (2000), "a diferença entre ter ou não e-mail, hoje um direito da cidadania, é a diferença entre ter ou não um emprego".

Há algum tempo atrás, os pobres eram criticados porque compravam televisores ao invés de gêneros considerados de primeira necessidade. ${ }^{3}$ Hoje em dia, os micro-computadores devem ser entronizados em local mais importante do que os antigos televisores. Em cada casa, pelo menos um micro (com acesso à Internet e ao correio eletrônico) é a exigência da chamada "democratização da informação". Afinal, a propaganda televisiva tenta mostrar que os provedores gratuitos estão aí para não "desmentir" que todos podem ser informados, instruídos e usufruir dos "progressos" da "modernidade".

Os números, porém, ao menos por enquanto, mostram que, embora pretendidos, tais direitos estão longe de serem efetivados. Rafael Mandarin Júnior, membro do Conselho Gestor da Internet, do Ministério de Ciência e Tecnologia, estima um total de somente 400 municípios brasileiros em que há provedor de acesso e de 4 a 5 milhões de usuários com acesso à Internet (Observatório da Imprensa, São Paulo, TV Cultura, 25/7/2000). Esses números, de acordo com reportagem de Marcello Billi (Folha de S. Paulo, B4, 3/7/2000), devem-se ao fato dos municípios com menos de 100 mil habitantes não terem provedor. Os grandes provedores, como UOL, IG, AOL, Terra e O Site, não atendem, juntos, a mais do que 260 cidades, que na maioria das vezes estão localizadas em regiôes metropolitanas. Billi avalia que "os custos para manter um provedor e o baixo número de assinantes potenciais explicam o desinteresse das empresas em prover acesso na maioria das localidades".

Há todo um cuidado, porém, para que esses números não ofusquem a imagem de um país considerado "emergente", novo slogan criado em substituição ao anterior "país em desenvolvimento". Tal emergência significa ser visto como candidato à participação na chamada globalização econômica. Para tanto, é preciso parecer "moderno" mesmo sem ter conseguido os requisitos essenciais da modernidade.

Como produtos artificiais, os estereótipos são apropriados pela mídia. Mudam-se os nomes, mas a condição de excluídos da chamada "globalização econômica" dos tais países "emergentes" continua a mesma, senão pior. Porém, a mudança de nomes cumpre a função de dar novo alento aos incautos que não percebem ou não querem perceber a condição de exclusão. Os slogans e a produção de notícias pelo jornalismo, como analisa Marcondes Filho (1986), criam uma "segunda natureza dos fatos sociais, diferente e, em muitos casos, oposta à verdadeira natureza das coisas". 
Um dos estereótipos recorrentes na história brasileira é o da modernização. Desde o século 18, intelectuais e políticos propugnam pela necessidade de modernização do Estado sem que a modernidade se efetive. ${ }^{4}$

Raymundo Faoro (1992, p. 8-9) expôs as diferenças entre "modernidade" e "modernização", já nos primórdios da introdução dos conceitos "neoliberais", na última década:

(...) a modernidade compromete, no seu processo, toda a sociedade, ampliando o raio de expansão de todas as classes, revitalizando ou removendo seus papéis sociais, enquanto que a modernização, pelo seu toque voluntário, se não voluntarista, chega à sociedade por meio de um grupo condutor, que, privilegiando-se, privilegia os setores dominantes. $\mathrm{Na}$ modernização não se segue o trilho da 'lei natural', mas se procura moldar, sobre o país, pela ideologia ou pela coação, uma certa política de mudança. (...) a ação social, que dela decorre, não parte da economia, como expressão da sociedade civil. Na modernidade, a elite, o estamento, as classes - dizemos para simplificar, as classes dirigentes - coordenam e organizam um movimento. Não o dirigem, conduzem ou promovem, como na modernização. (...) Talvez se possa dizer, ainda, que a modernização, ao contrário da modernidade, cinde a ideologia da sociedade, inspirando-se mais na primeira do que na segunda. (Grifos do autor)

Exemplo recente deste tipo de modernização, foi a decisão tomada pelo chamado grupo dos G-8, composto pelos sete países mais ricos do mundo mais a Rússia, durante reunião de cúpula, em Okinawa (Japão), em julho de 2000. Nesta reunião, os líderes desses países assinaram a Carta de Okinawa que, entre outras intenções, defende participação dos países pobres na "revolução da Internet" (Folha de S. Paulo, p. A-25, de 23/7/ 2000). Em manchete, a reportagem destaca: "G-8 Promete combater a exclusão digital”. Tal intenção, porém, já não é mais consensual e provocou protestos de ativistas do grupo "Coalizão pelo Alívio da Dívida”. De acordo com esta reportagem, este grupo de ativistas pôs fogo em um computador portátil, afirmando que "os pobres, quando têm fome, não podem comer bolos digitais" (Ann Pettifor, ativista do jubileu 2000-Reino Unido).

Slogans como "modernização", "países emergentes", "Terceira Via" (proposta de renovação política e econômica alternativa ao socialismo e ao liberalismo, idealizada, entre outros, por Anthony Giddens, 1998), 5 "Governança Progressista" etc., amplamente difundidos pela mídia mundial, cunham estereótipos capazes de produzir identidade. O estereótipo, analisa R. Bartes (1973, p. 57),

é a palavra repetida, fora de toda magia, de todo entusiasmo, como se fosse natural, como se por milagre essa palavra que retorna fosse a cada vez 
adequada por razões diferentes, como se imitar pudesse deixar de ser sentido como uma imitação: palavra sem-cerimômia, que pretende a consistência e ignora sua própria insistência. Nietzsche fez o reparo de que a "verdade" não era outra coisa senão a solidificação de antigas metáforas. Pois bem, de acordo com isso, o estereótipo é a via atual da "verdade", o traço palpável que faz transitar o ornamento inventado para a forma canonical, coercitiva, do significado.

Tal ideologia, difundida ad nauseum pela mídia, cumpre a função de reforçar o objetivo de unir a todos em um só pensamento. A "dimensão integradora”, característica das indústrias culturais, na concepção de Adorno e Horkheimer, estava e ainda está presente no rádio, no cinema e na televisão. Porém, a Internet ampliou essa possibilidade para o mundo e em tempo real. Como destaca Renato Ortiz (1994, p. 48-49), a Indústria Cultural é autoritária porque integra as pessoas a partir do alto. Ela impõe uma forma de dominação e promove uma padronização promovida por e através dos produtos culturais. Porém, de acordo com ele, isso só é possível porque esta padronização repousa em um "conjunto de mudanças sociais que estendem as fronteiras da racionalidade capitalista para a sociedade como um todo". E, nos tempos atuais, poder-se-ia completar, tal racionalidade se estende para o mundo todo.

Em interessante conjunção de autores, Sônia Marrach (1993, p. 138) explica que

o que distingue a mídia das outras organizações burocráticas é que nela a violência simbólica se assenta no fascínio do meio. $\mathrm{O}$ desenvolvimento das organizações que produzem cultura é concomitante ao processo de 'desencantamento do mundo' e perda do sentido. A mídia vem preencher o vazio do mundo desencantado com seu fascínio. E o fascínio surge onde o sentido é nulo. A fascinação, escreve Baudrillard, 'é a intensidade extrema do neutro (...) os leitores não vêem mais diferença entre os conteúdos que se refratam no vácuo - só o meio funcionando como efeito ambiente e se apresentando como espetáculo e fascinação'. 'O meio é a mensagem' profetizava MacLuhan. (...) As massas, elas não escolhem, não produzem diferenças, mas indiferenciação - elas mantêm a fascinação do meio, que preferem à exigência crítica da mensagem.

O contexto acima esboçado lança suas redes e chega na área educacional. Pretensamente "conectados" com as novas exigências tecnológicas, os responsáveis pelas escolas públicas tratam de viabilizar a possibilidade de os estudantes se informatizarem, inclusive acessando a Internet. O governo do estado de São Paulo, por exemplo, assinou convênio com a Telefônica para equipar 2.170 escolas da rede pública com tecnologia de acesso à 
Internet por cabo, que é dez vezes mais rápida que as conexões discadas. Serão atingidos 3,3 milhões de estudantes, número equivalente à metade da população escolar do estado. A Telefônica não cobrará pela instalação nem pelo provimento, mas somente pela mensalidade que, segundo acredita Fernando Xavier Ferreira, presidente da Telefônica no Brasil, venha a girar em torno da metade das tarifas cobradas na ocasião (final de 2001), certamente mais baixas do que as de hoje (Entrevista a Elio Gaspari, Folha de S.Paulo, A14, 4/6/2000).

Sobre o mesmo fato, Patrícia Cornils, no Jornal Valor, divulga que o governador Mário Covas credita ao presidente Fernando Henrique Cardoso esse projeto, que seria fruto de um compromisso assumido pela diretoria da Telefônica com o presidente. De acordo com ela, estaria nas pretensóes do governo federal viabilizar o acesso à Internet para as 20 mil escolas públicas do país, tendo o Ministro da Educação, Paulo Renato, reforçado essa meta, "apelando às demais operadoras para seguirem o exemplo da Telefônica” (Jornal Valor, B3, 30/5/2000). Na opinião de Cornils, porém,

o apelo do governo no sentido de levar a Internet às escolas seria melhor recompensado se o projeto do Fundo de Universalização das Telecomunicações (Fust), criado para democratizar o acesso à tecnologia, não estivesse parado no Congresso. Em parte, por culpa do próprio governo, porque o Ministério das Comunicaçôes e a Agência Nacional de Telecomunicaçōes (Anatel) disputam a prerrogativa de gerir recursos do fundo.

Enquanto isso, de acordo com ela, as contribuições de 1999 e 2000 já estariam perdidas, porque as operadoras somente seriam obrigadas a depositar 1\% de suas receitas líquidas no ano seguinte à criação do Fundo. Graças a essa demora, somente a Telefônica economizou, em 1999, cerca de $\mathrm{R} \$ 46$ milhões, o que é muito mais do que os $\mathrm{R} \$ 15$ a 20 milhões que a empresa se dispõe a investir até o final de 2001.

A notícia desse acordo (leia-se mensagem) ocorreu ao mesmo tempo em que os professores da rede estadual de ensino encontravam-se em greve, não somente por melhores salários, mas em defesa da escola pública. Entre as reivindicações, os professores pediam "diálogo e negociação". E complementavam:

Somos contra a reforma do ensino médio do governo, que compromete a qualidade do ensino. Queremos a organização do tempo escolar com seis aulas no diurno e cinco no noturno, classes com máximo de 35 alunos, mais segurança nas escolas, a volta de matérias importantes no currículo escolar, o fim da aprovação automática, piso de cinco salários mínimos e outras melhorias nas escolas estaduais. (Diretoria da Apeoesp, Folha de $S$. Paulo, A5, 4/6/2000) 
Estas reivindicações mostram a existência de problemas que deveriam ser solucionados antes ou, ao menos, concomitantemente à introdução dessa nova tecnologia nas escolas.

Porém, quando o assunto é informatização, as reais condições do ensino público no país ficam em segundo plano, quando não são totalmente esquecidas. Programas para melhorá-las certamente não teriam o mesmo impacto na mídia do que conectar as escolas à Internet.

Apenas como exemplo desses problemas, tomado aleatoriamente na própria mídia, cita-se aqui uma reportagem de Gilberto Nascimento, da Revista IstoÉ (10/05/2000), "Ensino reprovado: Sem repetência, alunos de escolas públicas chegam até a sexta série sem saber ler, escrever nem fazer as quatro operações aritméticas”.

A reportagem começa com uma frase absolutamente incompreensível: "No dina vit do de Abinu d doni come kicna do no ba Basinu terã mlazsa". De acordo com Nascimento, esta aparentemente insólita junção de letras é o resultado de uma triste realidade. Foi a tentativa de Welton, 11 anos, aluno da quarta série de uma escola municipal da zona leste de São Paulo, reproduzir um ditado singelo, sugerido por uma professora na sala de aula. Ele deveria ter escrito o seguinte: 'No dia 22 de abril, comemoramos os 500 anos do nosso Brasil, que é uma terra maravilhosa'. Para Nascimento, "Welton é apenas um exemplo de uma situação perversa reinante no ensino público". Para ele, atualmente a escola estaria formando, "subcidadãos" com "diploma e carteirinha", pois as crianças estão saindo da escola sem saber ler, escrever e fazer as quatro operaçôes aritméticas. E, citando aquela frase já conhecida dos educadores, Nascimento conclui que os governantes "fingem investir em educação, a escola finge que ensina e o aluno finge que aprende", num círculo vicioso em que o dinheiro do contribuinte vai para o ralo.

Numa outra área da zona leste paulistana, o Jardim Santo Elias, a cerca de 20 quilômetros do Centro, a mesma reportagem de IstoÉ relata outro fato: o esforço de quatro irmãos para tentar repetir a mesma façanha de Welton. Sem sucesso, Roberto, 15 anos, Marcelo, 14, Diego, 12, e Rodrigo, 11,

contorceram-se de um lado para outro, tentaram 'colar' e depois olharam para o vazio. Seguiram-se dez minutos de um silêncio. Uma vizinha que os acompanhava saiu do quarto com os olhos marejados. Ao final, os garotos exibiram garranchos e sinais ininteligíveis. $\mathrm{O}$ mais velho, em vez do ditado, colocou no papel três das raríssimas palavras que conhece: amei, come e boi. Órfāos de pai e mãe, os quatro conseguem escrever apenas o nome e 
não lêem nada, nem fazem contas. Roberto está matriculado na quinta série, numa escola municipal. Rodrigo e Marcelo, alunos da quarta série, e Diego, da segunda, estudam em outra, estadual. Freqüentam as aulas regularmente. Segundo Roberto, nunca fazem exercícios na sala de aula porque não entendem o que a professora pede. Ao ser perguntado como os professores reagem diante do fato de ele não saber ler, o menino não soube responder. Lágrimas começaram a descer de seu rosto. 'O que mais eu queria na vida era ler', lamenta.

Ainda de acordo com a reportagem, ao ver o que nove estudantes do ensino fundamental escreveram, o ministro da Educação, Paulo Renato Souza, teve uma reação de espanto: "É o fracasso da escola. Ela tem de fazer o aluno aprender. Temos de cobrar e exigir dedicação dos professores. Precisamos trocar essa cultura da reprovação, mas com avaliação." (Grifos meus).

O ministro parece reconhecer a deficiência do ensino, mas, enfatiza a reportagem, "não se cansa de dizer que nunca nenhum governo fez tanto pela educação no Brasil". De fato, o ministro sabe utilizar a mídia a favor de suas medidas e programas, independentemente de seus possíveis méritos ou deméritos. Conseguiu criar, nesses seis anos à frente do MEC, uma imagem de administração e de administrador eficiente, racional e empreendedor. Soube relacionar os programas de avaliação com a idéia de melhoria da qualidade de ensino como se aquela resultasse automaticamente nesta. Contudo, o que se viu foram situações, como diz o ditado popular, que poderiam ser consideradas cômicas se não fossem trágicas. Faculdades e universidades comprando livros aos quilos (literalmente, sem se importar com os títulos e autores), professores correndo para os "programas de pósgraduação" com as menores exigências possíveis, contratação de profissionais pelo título sem considerar méritos acadêmicos etc.

Nada disso, porém, parece ter influído, ainda, no ensino fundamental. Voltando à reportagem citada, professores e diretores entrevistados garantem que o drama de Welton ou o de Roberto e seus irmãos repetem-se em qualquer escola localizada em regióes pobres. Dizem que hoje não podem "reprovar ninguém". Segundo eles, quando se descobrem casos como esses, as secretarias de educação costumam abrir sindicância e somente os professores acabam penalizados, enquanto o governo não cumpre a sua parte. Alunos chegam até a sexta série sem saber ler, de acordo com os professores, porque grande parte deles necessita também de acompanhamento psicológico, tratamento médico ou atenção e dedicação exclusiva, o que a escola não estaria preparada para oferecer. Certamente a informatização aparece mais na mídia do que a construção de mais um posto de saúde e formação continuada de professores, por exemplo. 
Na mesma reportagem, Maria Moreira Fernandes, responsável pela Coordenadoria de Ensino da Região Metropolitana de São Paulo, órgão da Secretaria Estadual de Educação, contesta as afirmações dos professores: "Hoje o professor recebe por três horas a mais para dar reforço ao aluno que não consegue progredir no horário normal de aulas. Toda a rede também recebe por mais duas horas adicionais para discutir propostas pedagógicas. A competência coletiva deve ser colocada a serviço da aprendizagem do aluno."

A psicóloga e especialista em educação, Cenise Monte Vicente, excoordenadora do programa de combate à repetência escolar Acelera Brasil, do Instituto Ayrton Senna, também não poupa os professores. "Mesmo na quinta série, eles têm que saber alfabetizar. Não podem colocar a culpa só no sistema de avaliação, na família, no governo. $\mathrm{O}$ problema não está no sistema." (Grifos meus). Para ela, "o professor se encontra num estágio de 'solidariedade inoperante'. Eles se sentem impotentes para resolver o problema e acham que a solução está fora de seu âmbito. Não se sentem responsáveis" (idem). Mas, se isso é verdade, quais seriam as causas dessa pretensa irresponsabilidade? Ninguém fala em salários, condiçôes de trabalho, tipos diferenciados de contratação etc.

$\mathrm{Na}$ semana seguinte (27/5/2000), a Revista volta ao assunto com nova reportagem de Gilberto Nascimento. A manchete foi a seguinte: "Ministério reconhece alto índice de analfabetismo e ensaia reação". De acordo com a reportagem, o Ministério da Educação deveria lançar, até o final do ano, o Programa de Formação de Professores Alfabetizadores para tentar combater o problema de alunos de até quinta e sexta séries da escola pública que não sabem ler nem escrever. Para tanto, o ministro Paulo Renato Souza tornaria prioritário esse programa. Tal decisão, de acordo com Nascimento, teria sido tomada depois da repercussão daquela reportagem anterior (10/5/2000), que havia exibido os rabiscos ininteligiveis feitos por estudantes de escolas públicas da periferia de São Paulo.

Nascimento reafirma que, com a adoção do programa de progressão continuada (que elimina a repetência) em grande parte do país, alunos com as mesmas dificuldades dos meninos entrevistados na reportagem anterior também passariam a ser aprovados automaticamente. Como conseqüência, de acordo com ele, "a escola pública brasileira começou a produzir analfabetos com diploma". (IstoÉ, 27/5/2000).

Atualmente, $30 \%$ dos estudantes de primeira a quarta séries que repetem de ano sistematicamente - em regiôes onde não existe a aprovação automática - são alunos que não sabem ler nem escrever. Em algumas áreas do interior da Bahia, esse índice chega a 45\% em cada sala de aula. A 
constatação desses números foi feita por educadores ligados ao projeto Acelera Brasil, do Instituto Ayrton Senna e do BNDES, que oferece cursos de "aceleração" para 52 mil alunos repetentes em 258 municípios brasileiros. A diferença desse método é o resultado: os alunos aprendem e recuperam o tempo perdido, segundo Viviane Senna, presidente do Instituto Ayrton Senna. De acordo com ela, "oitenta e quatro por cento dos estudantes saltam das primeiras séries para a quarta ou quinta. E essa avaliação é 'auditada' externamente pela Fundação Carlos Chagas.” Na rede normal de ensino, a dificuldade hoje é saber se o professor está preparado para conseguir bons resultados junto a seus alunos. "Se estiver, ele vai conseguir. A gente sabe que isso é possível, mas não é fácil. Exige um preparo profissional, que infelizmente não está disponível aos professores”, observa a especialista Telma Weisz, doutora em Psicologia da Aprendizagem e consultora do Ministério da Educação (idem).

Dados do Programa Acelera Brasil indicaram que, no início do programa, 45\% de alunos baianos não sabiam ler. Técnicos do Ministério da Educação dizem que, em certas regiōes, já se chegou a detectar um índice de $75 \%$ de alunos matriculados na quarta série que não liam nem escreviam. Exames feitos no ano passado pelo Sistema de Avaliação do Ensino Básico (Saeb), do MEC, mostraram que apenas 10\% dos alunos da quarta série aprendem Matemática satisfatoriamente. Os ensinamentos de Língua Portuguesa surtem efeito somente para 42\% dos estudantes da rede pública. E os critérios sobre o que seria "ensino satisfatório", afinal, podem variar bastante. Telma Weisz, apesar de ser favorável à progressão continuada, reconhece que a situação se agrava: "Agora, as salas de aula continuam divididas entre 'os alunos que vão' e 'os que não vão', com uma pequena diferença: todos passam de ano, mas só alguns vão aprender”. De acordo com ela, "os índices de reprovação ao final da primeira série sempre giraram em torno de 50\%. Na aprovação por ciclos, conseguiram-se resultados melhores. O público leigo precisa saber que o que existia antes é tão ruim ou pior." (idem).

Walter Takemoto, diretor do Departamento de Políticas do Ensino Fundamental do Ministério da Educação, diz que o Ministério quer envolver as universidades públicas e privadas nesse programa de formação de alfabetização. $\mathrm{O}$ objetivo de tal programa seria combater o analfabetismo nas quarta e quinta séries, além dos altos índices de evasão, repetência e defasagem entre idade e série.

A sensação (para não dizer desconfiança) está se generalizando entre os educadores. De acordo com a reportagem, "o governo hoje tem a pre- 
ocupação de passar os alunos a qualquer custo para tentar mostrar ao FMI que não há mais analfabetos no Brasil.” Reclamaçôes assim repetem-se em todo o País. Por isso, professores da zona sul de São Paulo, juntamente com pais e alunos, foram às ruas pedir mais investimentos na escola pública. Se o governo, enfim, reconhece a precariedade do ensino e até repete o mesmo discurso dos educadores, espera-se que possa surgir uma luz no fim do túnel.

Esta situação evidencia alguns dos paradoxos da política educacional brasileira. Algumas escolas públicas equipadas com salas de leitura, TVs, vídeos e, até 2001, conectadas à Internet. As demais continuam produzindo analfabetos, "analfabetos funcionais" e, futuramente, se continuar a falta de uma política efetiva de formação e atualização de professores, "analfabetos ponto com".

Não se trata aqui de negar a importância dos meios de comunicação na escola, uma vez que, como diz Octávio Ianni (1999, p. 15), "além da competição evidente ou implícita entre os meios de comunicação de massas, ocorrem freqüentes irrupções de fatos, situações, relatos, análises, interpretações e fabulações que pluralizam e democratizam a mídia”. ${ }^{7}$ Porém, como ele mesmo define,

O que singulariza a grande corporação da mídia é que ela realiza limpidamente a metamorfose da mercadoria em ideologia, do mercado em democracia, do consumismo em cidadania. Realiza limpidamente as principais implicações da Indústria Cultural, combinando a produção e reprodução do capital; e operando decisivamente na formação de "mentes" e "corações", em escala global. (p.17)

É como se o "príncipe eletrônico" ${ }^{8}$ fosse resolver os problemas de aprendizagem e informação proporcionando a tão desejada inserção social. Porém, como alerta o mesmo Ianni,

Está em curso, ao acaso ou deliberadamente, um surpreendente, fundamental e inquietante processo de dissociação entre existência e consciência: ou condiçóes e possibilidades da existência e condições e possibilidades da consciência. Quando se desenvolvem e aplicam as tecnologias eletrônicas, informáticas e cibernéticas, agilizando e generalizando os meios de comunicação, informação e propaganda, as condições e possibilidades da consciência passam a descolar-se contínua ou reiteradamente da experiência, realidade ou existência.

Simultaneamente à dissociação entre existência e consciência, desenvolvemse outros, novos e muito diferentes significados do espaço e tempo, ser e 
devir, pensar e sentir, explicar e imaginar. Torna-se possível utilizar metáforas tais como as seguintes: mundo sem fronteiras, terra-pátria, aldeia global, fim da geografia, fim da história. Esse é o clima mental, isto é, virtual em que se formam expressōes destinadas a taquigrafar aspectos desse mundo virtual: multimídia, interface, internet, hipertexto, ciberespaço, desterritorialização, miniaturização, mundialização, globalização, planetarização. (Idem, p. 26-27)

Esse rumo, seguido pelos países ditos emergentes, "orientados" por aqueles considerados desenvolvidos, leva-os a se distanciar cada vez mais da realização dos anseios de liberdade, autonomia, livre arbítrio e, por que não dizer, de soberania nacional e uma nova organização mundial que proporcione uma maior igualdade social e econômica. Ao contrário, acentuam a divisão em um "universo orwelliano", fundado, como entende Umberto Eco, sobre três classes não propriamente marxistas: "a classe dos que interagem ativamente com a rede [de Internet], os que recebem e emitem mensagens, a pequena burguesia dos utilizadores passivos [...] e a classe proletária, que só verá televisão" (Umberto Eco, em entrevista ao Jornal Libération, publicada na Folha de S. Paulo, em 10 jan. 2000).

Diante disso, Eco indica um possível encaminhamento para que essa divisão seja superada. A solução, ele diz, “é externa à Internet”. É a "educação". De acordo com ele, "para permitir que todas as crianças atinjam essa aristocracia de massa, na escola é preciso aprender a programar, e não simplesmente a utilizar software. [...] Se ensinarmos uma criança a programar em 'Basic' ou 'Pascal' (duas linguagens de informática), o enorme exercício mental envolvido as tornará senhoras dos computadores".

Porém, como ensinar alunos que não sabem ler ou não entendem o que lêem a programar? Parece tarefa impossível, pois se trata de, além de superar os objetivos e métodos de ensino praticados, superar a condição de subsunção imposta com toda força pela mídia. Como enfatizam Adorno \& Horkheimer (1986, p. 114),

o terreno no qual a técnica conquista seu poder sobre a sociedade é o poder que os economicamente mais fortes exercem sobre a sociedade. A racionalidade técnica hoje é a racionalidade da própria dominação. Ela é o caráter compulsivo da sociedade alienada de si mesmo. (...) Por enquanto, a técnica da Indústria Cultural levou apenas à padronização e à produção em série, sacrificando o que fazia a diferença entre a lógica da obra e a do sistema social. Isso, porém, não deve ser atribuído a nenhuma lei evolutiva da técnica enquanto tal, mas à sua função na economia atual. A necessidade que talvez pudesse escapar ao controle central já é recalcada pelo controle da consciência individual. 
Assim, as questôes da instrução, do desenvolvimento e da formação individual passam necessariamente pelo crivo das metas sociais. Como aponta Zuin (1999, p. 2), "o sonho da formação (Bildung) sempre foi o de corresponder ao resultado inevitável de uma sociedade que se libertou das amarras morais e materiais correlatas aos regimes sociais pré-capitalistas". Nessa sociedade, pela primeira vez na história da humanidade, a cidadania, cujo conceito representa a concretização da essência da formação, seria universalizada, deixando de ser um privilégio de determinados grupos sociais.

Porém, como realizar esse sonho, hoje, aqui no Brasil, quando a democratização da informação, do saber, dos bens culturais produzidos pela humanidade, enfim, dos valores básicos e do exercício da cidadania parecem meras ilusões dos que ainda teimam em acreditar em uma sociedade mais justa, igualitária e solidária?

Respostas a essas perguntas estão sendo tentadas e testadas justamente por aqueles que, apesar de tudo, acreditam na capacidade de criação e superação da condição de alienação e exclusão em que se encontram pessoas e povos. Diversas teorias e metodologias, hoje experimentadas nas escolas, pretendem alcançar os objetivos de uma formação pessoal e social que possibilitem às pessoas (e não apenas ao indivíduo já previamente definido pela concepção liberal) superar entraves impostos por uma concepção utilitária, utilitarista e consumista de homem e de sociedade. Porém, para que tais teorias e métodos não se transformem de meios em fins, há que se fazer um esforço para não perder de vista os objetivos últimos de uma formação emancipadora para não cair na tentação dos modismos pedagógicos ou na caricatura de concepções psicológicas, políticas e filosóficas, transformados em "métodos" de ensino e aprendizagem.

\section{Notas}

1. Dahl define "sistema dual" como aquele em que "para os indivíduos que estão integrados, existem mecanismos efetivos de participação e influência, ao passo que para os que ficam de fora há um regime de coerção e, em casos extremos, de terror" (Dahl, 1971, p. 3).

2. Weffort (1992, p. 23) observa que "em uma sociedade democrática os indivíduos pertencem a diferentes classes, o que ocasiona desigualdades sociais, mas não existem cidadãos de segunda classe, pelo menos não na magnitude registrada no Brasil (e na maioria dos países latino-americanos)".

3. De acordo com Luis Costa (2000), "a televisão crava 50 anos no Brasil e a sensação é de que faz parte da paisagem. Afinal ela é mais importante para o brasileiro do que geladeira. Segundo o IBGE, há 2 milhôes de casas com televisor no País que dispensaram o luxo de ter o outro eletrodoméstico. Uma novela vale o ônus de ver comida em casa estragando na cozinha” ( $O$ Estado de S. Paulo, 18 jun. 2000).

4. A pauta da modernização foi freqüente entre os chamados Déspotas Esclarecidos do século 18 . $\mathrm{O}$ Marquês de Pombal, por exemplo, já colocava de forma enfática a necessidade de "modernizar" o Reino português para superar $\mathrm{o}$ atraso nacional. 
5. Giddens, em entrevista a Ricardo Grinbaum (Folha de S. Paulo, A12, 22 maio 2000), afirma que "muitas pessoas usam a Terceira Via por razōes políticas, como um rótulo para se legitimar". Ele diz ter estado em alguns países em que quase todos os partidos se apresentavam como representantes da Terceira Via. "É ridículo", ele se irrita. Porém, admite que "o fato é que a idéia se espalhou de uma maneira surpreendente por todo mundo". E, poder-se-ia acrescentar, da forma como convém.

6. Governança progressista foi um novo termo criado como sinônimo de Terceira Via e usado em reunião de representantes de 16 países, em Berlim, em junho de 2000 (Jornal Valor, C18, 2-4 jun. 2000). Nesta conferência, apesar de vozes já terem se pronunciado sobre a superação das estruturas internacionais Organização da Nações Unidas, Fundo Monetário Internacional, Banco Mundial, G 7 (grupo dos sete países mais ricos do mundo), o próprio presidente do Brasil, Fernando Henrique Cardoso, não acredita que, das discussões de Berlim, nasça um "receituário concreto" para a "Governança Progressista" (Folha de S. Paulo, A12, 3 jun. 2000).

7. Tal pluralismo existe de fato na mídia, principalmente na imprensa escrita, como aqui demonstrado.

8. Para Ianni (1999, p. 14) o "príncipe eletrônico" não é bem o condottiero, de Maquiavel, nem o partido político orgânico, de Gramsci, mas "ultrapassa os descortinos e as atividades dessas duas figuras clássicas da política. O príncipe eletrônico é uma entidade nebulosa e ativa, presente e invisível, predominante e ubíqua, permeando continuamente todos os níveis da sociedade, nos âmbitos local, nacional, regional e mundial, sempre em conformidade com os diferentes contextos socioculturais e político-econômicos desenhados no novo mapa do mundo".

\title{
Cultural INDUSTRY: SOME POLITICS, CUlTURAL AND SOCIAL DETERMINATIONS IN THE EDUCATION
}

\begin{abstract}
This paper analyzes the persistence of both the apartheid and social exclusion despite the supposed information democratization that would be made possible by the introdution of new technologies in the communication means at educational and institutions curricula. Such new technologies (TVs, VCRs, computers connected to the Internet), having been adopted by the cultural industry, continue "producing" illiterate people and known as functional illeterate as well as, lately, the "illeterate dot com". These resources have generated neither greater knowledge nor individual participation in the political decisions and in the socio-cultural goods restricted to a minority of people who could be called "citizens". The overcome offashion pedagogic aiming critical and creative education driven to emancipating objectives is still a task to be accomplished.
\end{abstract}

Key words: Cultural Industry, Technology and Social Exclusion, Education and Technologies. 
Referências bibliográficas

ADORNO, Theodor W. \& HORKHEIMER, Max. Dialética do Esclarecimento. Trad. Guido Antonio de Almeida (2a ed.), Rio de Janeiro: Jorge Zahar, 1985.

BARTES, Roland. O Prazer do texto. São Paulo: Perspectiva, 1973.

COSTA, LUIS. Os paradoxos da TV no seu cinqüentenário. O Estado de S. Paulo, São Paulo, Caderno Cultura, 18 jun. 2000.

DAHL, Robert. Polyarchy - Participation and opposition. New Haven: Yale University Press, 1971.

DIMENSTEIN, Gilberto. "www.ignorancia.com.br". Folha de S. Paulo, São Paulo, 6 fev. 2000, Caderno 3, p. 16.

ECO, Umberto. Entrevista ao Libération. Folha de S. Paulo, São Paulo, 10 jan. 2000, Caderno 1, p. 8.

FAORO, Raymundo. A questão Nacional: A modernização. In: BosI, Alfredo (ed.), Estudos Avançados, no 14, vol. 6, jan./abr. 1992, São Paulo: USP.

IANNI, Octávio. O príncipe eletrônico. Perspectivas, Revista de Ciências Sociais, vol. 22, São Paulo: Unesp, 1999.

NASCIMENTO, Gilberto. Ensino reprovado: Sem repetência, alunos de escolas públicas chegam até a sexta série sem saber ler, escrever nem fazer as quatro operaçōes aritméticas. IstoÉ, São Paulo, 10 maio 2000.

. Ministério reconhece alto índice de analfabetismo e ensaia reação. IstoÉ, São Paulo, 27 maio 2000.

ORTIZ, Renato. A moderna tradição brasileira. $5^{a}$ ed. São Paulo: Brasiliense, 1994.

SADER, Emir. Trabalho e Democracia. Folha de S. Paulo, São Paulo, A3, 4 jun. 2000.

SANTOS, Milton. Da cultura à Indústria Cultural. Folha de S. Paulo, São Paulo, 19 mar. 2000, Caderno Mais.

WEFFORT, Francisco C. Qual democracia? São Paulo: Companhia das Letras, 1992.

ZUIN, Antônio A. S. Induistria Cultural e educação: O novo canto da sereia. Campinas: Autores Associados/Fapesp, 1999. 